IOS Press

\title{
Obituary
}

\section{Remembering Hans Rosling (1948-2017)}

Professor Hans Rosling has passed away. He died on February 7. He was a visionary and a great educator who made data and numbers come alive. He made complex issues easier to comprehend by showing us how to use data to visualize intricate relationships. He gave us bubble charts, animated scatterplots and "The Joy of Stats."

Hans Rosling shared his vision for the use of official statistics and the role of National Statistical Systems in a manuscript. In 2007, he wrote:

"....It can be assumed that new technology for visualization and animation, in combination with new ways of achieving uniformed format for large amounts of statistics, will soon induce considerable changes in the use and understanding of public statistics. A close linking of statistical information with geographical information will enhance the value of both systems. The best way to plan for the future is thus unclear. However, these uncertainties are probably best regarded as opportunities." (Excerpted from "Visual Technology Unveils the Beauty of Statistics and Swaps Policy From Dissemination to Access," Vol 24, No 1-2 (103-104).)
Hans Rosling continuously inspired statisticians worldwide. Just a few month ago, in January, he participated via SKYPE in the first United Nations World Data Forum held in Cape Town. The International Association for Official Statistics and its Journal join the statistical community in mourning his death. We extend our deepest sympathy to his family.

\author{
Kirsten West \\ Editor-in-Chief \\ SJIAOS (kwestiaos@gmail.com)
}

Ola Awad

President

IAOS (ola@pcbs.gov.ps) 